\title{
PERANCANGAN ANIMASI INTERAKTIF PEMBELAJARAN BAHASA PERANCIS LEVEL SMA
}

\author{
Noer Hikmah ${ }^{1}$, Narti $^{2}$, Suwesti Narita ${ }^{3}$ \\ ${ }^{1,3}$ Jurusan Sistem Informasi, ${ }^{1,3}$ Universitas Bina Sarana Informatika, ${ }^{2}$ STMIK Nusa Mandiri \\ e-mail: *1'noer.nhh@bsi.ac.id, ${ }^{2}$ nartishaka@gmail.com, ${ }^{3}$ shuwesti.narita@gmail.com
}

\begin{abstract}
Interactive animation is a medium for packing information so it can be displayed with interesting. the concept of animation learning French language which become an alternative means to train basic speaking french language. Equipped with animation and audio for every word base that aims to make this application more interesting, and added with a menu of conversation exercises and quis that can train the user knowledge of the basic French words that have been studied. Packaged in the form of visual and audio learning media using Macromedia Flash 8 and Adobe Photoshop cs5 applications. This work is expected to be a learning medium that can help users to understand the French language.
\end{abstract}

Keywords_Animation, Learning Media, Macromedia Flash

\begin{abstract}
Abstrak - Animasi interaktif merupakan sebuah media untuk mengemas informasi sehingga dapat ditampilkan dengan menarik. konsep animasi pembelajaran bahasa perancis yang menjadi sarana altematif untuk melatih berbicara dasar bahasa perancis. Dengan dilengkapi animasi serta audio untuk setiap dasar kata yang bertujuan untuk membuat aplikasi ini menjadi lebih menarik, serta ditambahi dengan menu latihan percakapan dan quis yang dapat melatih pengetahuan pengguna akan dasar kata bahasa perancis yang sudah dipelajari. Dikemas dalam bentuk visual dan audio media pembelajaran yang menggunakan Macromedia Flash 8 dan aplikasi Adobe Photoshop cs5. Karya ini di harapkan menjadi media pembelajaran yang bisa membantu pengguna untuk mengerti bahasa perancis.
\end{abstract}

Kata Kunci-Animasi, Media Pembelajaran, Macromedia Flash

\section{A. Pendahuluan}

Dunia pendidikan merupakan salah satu dari pengguna teknologi yang semakin berkembang. Seperti halnya komputer yang dapat dipergunakan sebagai alat bantuan dalam proses belajar mengajar yang mempunyai fungsi sebagai media tutorial. Berdasarkan besarnya peranan komputer ataupun teknologi dalam dunia pendidikan, komputer dapat dimanfaatkan sebagai media pembelajaran yang begitu menarik bagi pelajar. Jika anak hanya membaca buku saja, tentunya akan menjadi cepat bosan berbeda jika suatu pembelajaran diaplikasikan kedalam sarana multimedia yang kreatif dan menarik. Bahasa Perancis (le français, la langue française) adalah salah satu bahasa paling penting dari kelompok bahasa Roman setelah bahasa Spanyol dan bahasa Portugis. Bahasa Perancis merupakan bahasa yang paling banyak dituturkan ke-11 di dunia. Hingga tahun 1999, bahasa ini dituturkan oleh lebih dari 77 juta penduduk di dunia sebagai bahasa ibu dan oleh 128 juta jiwa lainnya sebagai bahasa kedua. Secara umum bagi pelajar hal ini akan menjadi lebih mudah dan lebih menarik dalam mempelajari bahasa tersebut. Jika pelajar mempelajari pengucapan dengan benar, dan kemudian merasa senang, maka mereka akan dapat berbicara lancar dalam bahasa tersebut.

\section{B. TINJAUAN PUSTAKA}

Menurut Veeger dalam Janu Murdiyatmoko (2007:101) bahwa:

Sosialisasi adalah suatu proses belajarmengajar. Melalui sosialisasi, individu belajar menjadi anggota masyarakat yang prosesnya tidak semata-mata mengajarkan pola-pola prilaku social kepada individu, tetapi juga individu tersebut mengembangkan dirinya atau melakukan proses pendewasaan diri.

MenurutSuprapto (2009:147) bahwa:

Penyuluhan merupakan aktivitas komunikasi yang mengelola informasi dengan tujuan untuk perubahan sikap. Karena tujuannya adalah perubahan sikap, maka pemilihan dan penggunaan medianya adalah yang mampu mengubah perilaku hallayak. Dalam kaitan ini, maka media yang relevan untuk penyuluhan adalah media tatap muka atau interpersonal media. 
Multimedia, ditinjaudaribahasanya, terdiridari 2 kata, yaitu multi dan media. Multi memiliki arti banyak atau lebih dari satu. Sedangkan media merupakan bentuk jamak dari medium, juga diartikansebagai saran, wadah, ataualat. Istilah multimedia sendiri dapat diartikan sebagai transmisi data dan manipulasi semua bentuk informasi, baik berbentuk kata-kata, gambar, video, musik, angka, atautulisantangan di mana dalam dunia komputer, bentuk informasi tersebut diolah dalam bentuk data digital (Darma:2009:1). Definisi lain mengatakan multimedia merupakan kombinasi teks, seni, suara, gambar, animasidan video yang disampaikan dengan computer atau dimanipulasi secara digital dan dapat disampaikan dan dikontrol secara interaktif (Binanto:2010:2).

Animasi adalah usaha untuk membuat presentasi statis menjadi hidup, yang merupakan perubahan visual sepanjang waktu yang member kekuatan besar pada proyek multimedia dalam halaman web yang dibuat Binanto(2010:219).

Menurut Madcoms (2007:3) bahwa:

Macromedia Flash Profesional 8 adalah sebuah program animasi yang telah banyak digunakan oleh para Animator untuk menghasilkan animasi yang profesional. Di antara program-program animasi, program Macromedia Flash Profesional 8 merupakan program yang paling fleksibel dalam pembuatan animasi, seperti animasi interaktif, game, company profile, presentasi, movie, dan tampilan animasi lainnya.

\section{Menurut Al fatta (2007:169) bahwa:}

Pengujian system merupakan proses mengeksekusi system perangkat lunak untuk menentukan apakah system perangkat lunak tersebut cocok dengan spesifikasi system dan berjalan sesuai dengan lingkungan yang di inginkan.

\section{B. METODE PENELITIAN}

Metode Pengembangan Perangkat Lunak

Metode yang digunakan pada pengembangan perangkat lunak ini menggunakan model water fall (Sommerville 2011:31) yang terbagi menjadi 3 tahapan, yaitu:

1. Analisis Kebutuhan
Sistem pelayanan, kendala, dan tujuan ditetapkan melalui konsultasi dengan pengguna sistem. Mereka kemudian didefinisikan secara rinci dan berfungsi sebagai spesifikasi sistem.

2. Perancangan Sistem dan Perangkat Lunak

Proses perancangan sistem memerlukan alokasiyang dilegalisasikan baik perangkat keras atauperangkat lunak sistem dengan membentuk sistem yang arsitektur secara keseluruhan. Perancangan sistem melibatkan identifikasi dan menggambarkan abstraksi sistem perangkat lunak yang fundamental dan hubungannya secara interface terhadap user.

3. Implementasi dan Pengujian Unit

Pada tahap ini, perancangan perangkat lunak direalisasikan sebagai serangkaian program atau unit program. Kemudian pengujian unit melibatkan verifikasi bahwa setiap unit program telah memenuhi spesifikasinya.

\section{Teknik Pengumpulan Data}

\section{Metode Wawancara (Interview)}

Pengumpulan data dengan menggunakan proses tanya jawab secara langsung kepada guru sekolah yang terkait.

2. Metode Pengamatan (Observasi)

Pengumpulan data dilakukan dengan melihat objek penelitian langsung ke lapangan, dengan mengunjungi sekolah menengah keatas (SMA) yang terkait dengan sebagai pedoman pembuatan Tugas Akhir.

3. Metode Studi Pustaka (Literature)

Penulisan pustaka dilakukan untuk mengumpulkan data dengan informasi melalui buku-buku baik online maupun ofline.

\section{HASIL DAN PEMBAHASAN}

\subsection{Rancangan Animasi}

\section{a. Analisa Kebutuhan}

analisis kebutuhan pemakai / pengguna pada program animasi pengenalan bahasa perancis dengan rincian sebagai berikut:

\section{Profil}

Keterangan pembuatan program/aplikasi dengan software danpenjelasannya.

2. Tujuan pembelajaran 
Aplikasi ini bertujuan untuk membantu para pemula dalam mempelajari bahasa perancis.

3. Materi

Dasar-dasar kata dari bahasa perancis dalam bentuk tulisan, pembacaan, dan pengucapan bahasa perancis yang baik dan benar. Terbagi menjadi empat menu yaitu keluarga, angka, hewan, dan ungkapan.

4. Latihan

Mendengarkan dan berlatih percakapan pengenalan diri dalam Bahasa perancis.

5. Quis / pertanyaan

Pada menu ini terdapat evaluasi pembelajaran dari menu materi dan latihan.

b. Rancangan Storyboard

1. Menu utama

\begin{tabular}{|l|c|l|}
\hline \multicolumn{1}{|c|}{ VISUAL } & SKETSA & \multicolumn{1}{|c|}{ AUDIO } \\
\hline $\begin{array}{l}\text { Dalam Frame ini } \\
\text { terdapat 5 menu } \\
\text { yang bisa di pilih } \\
\text { antara lain: } \\
\text { Profil, Tujuan, } \\
\text { Materi, Latihan, } \\
\text { dan Quis }\end{array}$ & MENU UTAMA & $\begin{array}{l}\text { Musik : } \\
\text { Musik } \\
\text { Pembuka }\end{array}$ \\
\cline { 2 - 3 } & JUDUL & \\
\hline
\end{tabular}

Sumber: Hasil Penelitian (2017)

Gambar III.1 Menu Utama

\section{Menu Profil}

\begin{tabular}{|l|c|c|}
\hline \multicolumn{1}{|c|}{ VISUAL } & SKETSA & AUDIO \\
\hline \multirow{2}{*}{$\begin{array}{l}\text { Dalam Frame ini } \\
\text { menjelaskan } \\
\text { tentang } \\
\text { pembuatan } \\
\text { program dengan } \\
\text { software }\end{array}$} & $\begin{array}{c}\text { PENJELASAN } \\
\text { PEMBUATAN } \\
\text { PROGRAM }\end{array}$ & \multirow{2}{*}{$\begin{array}{l}\text { Musik : } \\
\text { No Musik }\end{array}$} \\
\cline { 2 - 2 } & $\begin{array}{c}\text { Software } \\
\text { Macromedia }\end{array}$ & $\begin{array}{c}\text { Software } \\
\text { Adobe } \\
\text { Photoshop }\end{array}$ \\
\cline { 2 - 2 } & \multicolumn{2}{|c}{} \\
\hline
\end{tabular}

Sumber: Hasil Penelitian (2017)

Gambar III.2Menu Profil
3. Menu Tujuan

\begin{tabular}{|l|c|c|}
\hline \multicolumn{1}{|c|}{ VISUAL } & SKETSA & AUDIO \\
\hline $\begin{array}{l}\text { Dalam Frame ini } \\
\text { menjelaskan } \\
\text { tentang maksud } \\
\text { dan tujuan } \\
\text { pembuatan } \\
\text { program }\end{array}$ & $\begin{array}{c}\text { PENJELASAN } \\
\text { MAKSUD } \\
\text { PEMBUATAN } \\
\text { PROGRAM }\end{array}$ & $\begin{array}{l}\text { Musik : } \\
\text { No Musik }\end{array}$ \\
\cline { 2 - 3 } & $\begin{array}{c}\text { PENJELASAN TUJUAN } \\
\text { PEMBUATAN } \\
\text { PROGRAM }\end{array}$ \\
\hline
\end{tabular}

Sumber: Hasil Penelitian (2017)

Gambar III.3 Menu Tujuan

4. Menu

Materi

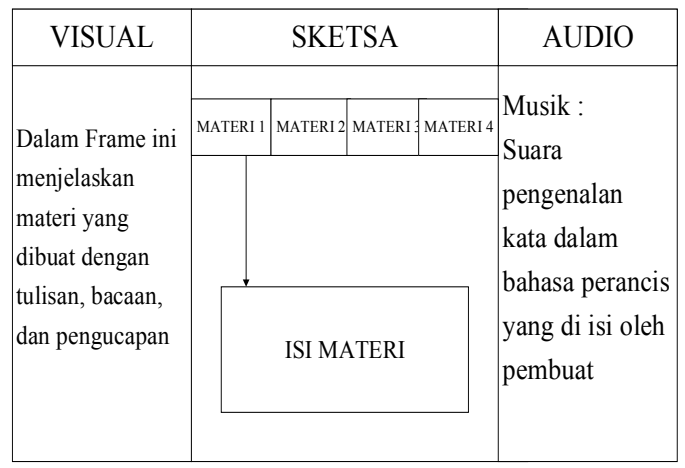

Sumber: Hasil Penelitian (2017)

Gambar III.4Menu materi

5. Menu Latihan

\begin{tabular}{|c|c|c|c|}
\hline VISUAL & \multicolumn{2}{|c|}{ SKETSA } & AUDIO \\
\hline \multirow{3}{*}{$\begin{array}{l}\text { Dalam Frame ini } \\
\text { menampilkan } \\
\text { latihan } \\
\text { percakapan } \\
\text { dengan di isi oleh } \\
\text { suara pembuat }\end{array}$} & GAMBAR 1 & GAMBAR 2 & \multirow{3}{*}{$\begin{array}{l}\text { Musik: } \\
\text { Suara } \\
\text { Percakapan } \\
\text { dalam bahasa } \\
\text { perancis yang } \\
\text { di isi oleh } \\
\text { pembuat }\end{array}$} \\
\hline & \multicolumn{2}{|c|}{$\begin{array}{c}\text { Slogan } \\
\text { Percakapan }\end{array}$} & \\
\hline & & & \\
\hline & & & \\
\hline
\end{tabular}

Sumber: Hasil Penelitian (2017)

Gambar III.5. Menu latihan 
5. Tampilan Menu Latihan

Menampilkan menu latihan yang berisikan percakapan yang di isi oleh suara pembuat program dan cara pengucapan untuk latihan pengenalan diri.

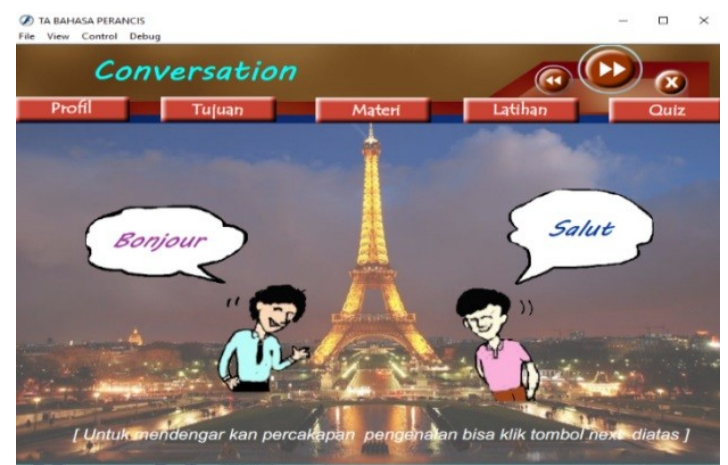

Sumber: Hasil Penelitian (2017)

Gambar III.11 Menu Latihan

6. Tampilan menu quis

Menampilkan sebuah pertanyaan dengan pertanyaan dari materi yang sudah di buat di aplikasi tadi dengan menarik

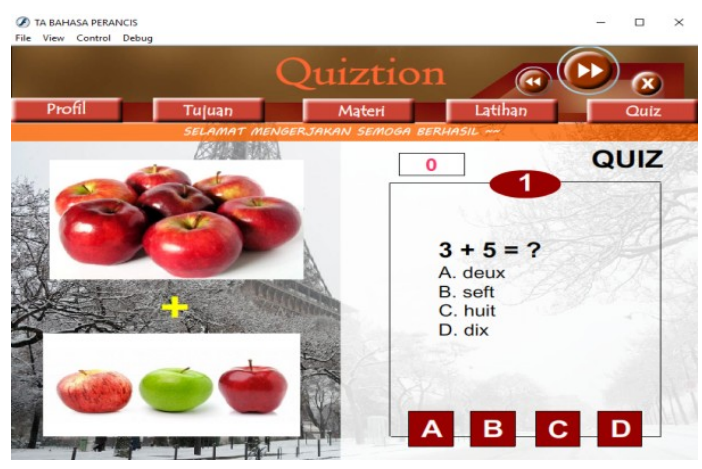

Sumber: Hasil Penelitian (2017) Gambar III.12 Menu Quis

\subsection{Pengujian Unit}

\section{A. Blackbox Testing}

Pengujian terhadap program yang dibuat menggunakan blackbox testing yang fokus terhadap proses masukan dan keluaran program.

\section{Pengujian Terhadap Form Profil}

Tabel III.1. Hasil Pengujian Blackbox Testing Halaman Profil

\begin{tabular}{|l|c|c|c|}
\hline \hline Input / Event & \multicolumn{1}{|c|}{ Proses } & $\begin{array}{c}\text { Output/Next } \\
\text { Stage }\end{array}$ & Hasil Pengujian \\
\hline Tombol Menu Profil & $\begin{array}{c}\text { on (release) } \\
\text { (gotoAndStop(2); } \\
\text { stopAllSounds); } \\
\text { Tombol Keluar }\end{array}$ & $\begin{array}{l}\text { Menu Profil } \\
\text { on (release) } \\
\text { fscommand("quit"); } \\
\text { gotoAndtop(1); }\end{array}$ & Sesuai \\
\hline \multicolumn{2}{|c|}{ Sumber : hasil penelitian (2017) } & Sesuai \\
\hline
\end{tabular}

Tabel III.2 Hasil Pengujian Blackbox Testing Halaman Tujuan

\begin{tabular}{|c|c|c|c|}
\hline Input / Event & Proses & $\begin{array}{c}\text { Output /Next } \\
\text { Stage } \\
\end{array}$ & Hasil Pengujian \\
\hline $\begin{array}{l}\text { Tombol Menu } \\
\text { Tujuan }\end{array}$ & $\begin{array}{l}\text { on (release) } \\
\quad \text { \{gotoAndStop(3); } \\
\text { stopAllSounds(); } \\
\text { s }\end{array}$ & Menu Tujuan & Sesuai \\
\hline Tombol Keluar & $\begin{array}{l}\text { on (release)\{ } \\
\text { fscommand("quit"); } \\
\text { gotoAndStop(1); }\end{array}$ & Menu Utama & Sesuai \\
\hline
\end{tabular}

Sumber : hasil penelitian (2017)

Tabel III.3. Hasil Pengujian Blackbox Testing Halaman Materi

\begin{tabular}{|c|c|c|c|}
\hline Input / Event & Proses & $\begin{array}{c}\text { Output/Next } \\
\text { Stage }\end{array}$ & Hasil Pengujian \\
\hline Tombol Menu Materi & $\begin{array}{l}\text { on (release) } \\
\quad \text { gotoAndStop(4); } \\
\text { stopAllSounds(); }\end{array}$ & Menu Materi & Sesuai \\
\hline Tombol Keluarga & $\begin{array}{l}\text { on (release) } \\
\text { \{gotoAndStop(4); } \\
\text { stopAllSounds(); }\end{array}$ & Materi Keluarga & Sesuai \\
\hline Tombol Number & $\begin{array}{l}\text { on (release) } \\
\text { \{gotoAndStop(5); } \\
\text { stopAllSounds(); } \\
\end{array}$ & Materi Number & Sesuai \\
\hline Tombol Animal & $\begin{array}{l}\text { on (release) } \\
\quad \text { (gotoAndStop(6); } \\
\text { stopAllSounds(); }\end{array}$ & Materi Animal & Sesuai \\
\hline Tombol Ungkapan & $\begin{array}{l}\text { on (release) } \\
\quad \text { gotoAndStop(7); } \\
\text { stopAllSounds(); }\end{array}$ & Materi Ungkapan & Sesuai \\
\hline Tombol Keluar & $\begin{array}{l}\text { on (release)\{ } \\
\text { fscommand("quit"); } \\
\text { gotoAndStop(1); }\end{array}$ & Menu Utama & Sesuai \\
\hline
\end{tabular}

Sumber : hasil penelitian (2017) 
Tabel III.4Hasil Pengujian Blackbox Testing Halaman Latihan

\begin{tabular}{|c|c|c|}
\hline Input/Event & Proses & Output/Next \\
Stage
\end{tabular}

Sumber : hasil penelitian (2017)

Tabel III.5 Hasil Pengujian Blackbox Testing Halaman Quis

\begin{tabular}{|c|c|c|c|}
\hline Input / Event & Proses & $\begin{array}{c}\text { Output/Next } \\
\text { Stage }\end{array}$ & Hasil Pengujian \\
\hline Tombol Menu Quis & $\begin{array}{c}\text { on (release) } \\
\text { (gotoAndStop(10); } \\
\text { stopAllSounds); } \\
\end{array}$ & Menu Quis & Sesuai \\
\hline Tombol Start & $\begin{array}{l}\text { on (release) \{ } \\
\text { gotoAndStop(11); } \\
\text { S }\end{array}$ & Soal & Sesuai \\
\hline Tombol Pilihan Ganda & 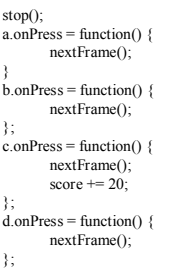 & Next Soal & Sesuai \\
\hline Tombol Back to Quis & $\begin{array}{l}\text { on (release) } \\
\text { \{gotoAndStop(10); }\end{array}$ & Menu Quis & Sesuai \\
\hline Tombol Keluar & $\begin{array}{l}\text { on (release) }\{ \\
\text { fsccommand("quit"); } \\
\text { gotoAndStop(1); } \\
\end{array}$ & Menu Utama & Sesuai \\
\hline
\end{tabular}

Sumber : hasil penelitian (2017)

\section{b.Penerimaan User Terhadap Animasi}

Dengan menyebar kuisioner bagi minimal 5 orang untuk mengetahui sejauh mana aplikasi ini berfungsi dengan baik serta bermanfaat bagi pengguna.

Tabel III.6. Pengujian Kuisioner

\begin{tabular}{|c|l|c|c||}
\hline NO & \multicolumn{1}{|c||}{ PERTANYAAN KUISIONER } & Ya & Tidak \\
\hline 1 & Apakah tampilan aplikasi dari pembelajaran bahasa perancis ini menarik ? & & \\
\hline 2 & $\begin{array}{l}\text { Apakah dengan aplikasi pembelajaran ini pengguna bisa mengerti dan } \\
\text { paham tentang dasar bahasa perancis ? }\end{array}$ & & \\
\hline 3 & $\begin{array}{l}\text { Apakah dengan aplikasi pembelajaran ini pengguna mendapatkan ilmu } \\
\text { tentang bahasa perancis ? }\end{array}$ & & \\
\hline 4 & $\begin{array}{l}\text { Apakah suara pengucapan bahasa perancis dalam aplikasi ini terdengar } \\
\text { jelas ? }\end{array}$ & & \\
\hline 5 & $\begin{array}{l}\text { Apakah dengan aplikasi pembelajaran ini pengguna mendapatkan materi } \\
\text { yang mudah di pahami ? }\end{array}$ & & \\
\hline 6 & $\begin{array}{l}\text { Apkah animasi pembelajaran dasar belajar bahasa perancis mudah di } \\
\text { operasikan / di jalankan? }\end{array}$ & & \\
\hline 7 & Apakah setiap fitur yang terdapat pada aplikasi ini berjalan dengan baik ? & & \\
\hline 8 & Apakah materi dari dalam bahasa perancisnya sudah bagus untuk pemula ? & & \\
\hline 9 & $\begin{array}{l}\text { Apakah dengan bantuan aplikasi pembelajaran ini masalah si pengguna } \\
\text { dapat diselesaikan? }\end{array}$ & & \\
\hline 10 & Apakah quis yang dibuat dalam aplikasi pembelajaran cukup menarik ? & & \\
\hline
\end{tabular}

Sumber : Hasil Penelitian (2017)

Ket: Beri tanda $\sqrt{ }$ pada jawaban yang di pilih.

Dari hasil survei terhadap aplikasi pembelajaran dasar belajar bahasa perancis dapat disimpulkan bahwa aplikasi ini telah mampu digunakan untuk membantu pengguna dalam metode pembelajaran yang mudah di pahami. Selain iti pengguna aplikasi tersebut juga cukup mudah di mengerti oleh pengguna awam.

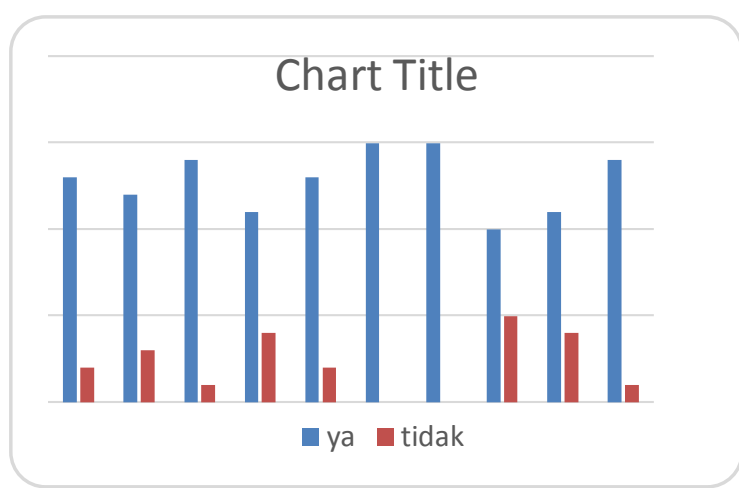

Sumber : hasil penelitian (2017)

Gambar III.13 Tampilan hasil quisioner

Tabel III.7. Tampilan Grafik Kuesioner Responden

\begin{tabular}{|l|l|l|l|l|l|l|l|l|l|l|}
\hline soal & 1 & 2 & 3 & 4 & 5 & 6 & 7 & 8 & 9 & 1 \\
\hline Ya & 1 & 1 & 1 & 1 & 1 & 1 & 1 & 1 & 1 & 1 \\
& 3 & 2 & 4 & 1 & 3 & 5 & 5 & 0 & 1 & 4 \\
\hline Tidak & 2 & 3 & 1 & 4 & 2 & 0 & 0 & 5 & 4 & 1 \\
\hline
\end{tabular}

Sumber: hasil penelitian (2017) 


\section{E. KESIMPULAN}

Berdasarkan penjelasan diatas maka dapat disimpulkan bahwa animasi interaktif pembelajaran bahasa perancis level SMA. Sebagai alat bantu tambahan bagi guru dalam proses belajar mengajar bahasa perancis pada tingkat SMA. Juga dapat memperkenalkan para siswa/i mengenai aplikasi macromedia flash adalah salah satu dari sekian banyak aplikasi yang dapat dijadikan alat bantu dalam membuat sebuah animasi interaktif dengan mudah. Dengan animasi ini diharapkan dapat membantu para siswa/i SMA dalam belajar bahasa perancis yang disajikan dengan berbagai fitur-fitur yang menarik yang dapat dipahami dengan jelas dan mudah.

\section{DAFTAR PUSTAKA}

[1] Al fatta, Hanif. 2007. Analisis dan Perancangan Sistem Informasi Untuk Keunggulan Bersaing Perusahaan dan Organisasi Modern. Yogyakarta: Andi.

[2] Binanto, Iwan. 2010. Multimedia Digital Dasar Teori dan Pengembanganya. Yogyakarta: Andi.

[3] Darma. S, Jarot. Ananda, Shenia. 2009. Buku Pintar Menguasai Multimedia. Jakarta: Mediakita.

[4] Madcoms. 2007. Mahir Dalam 7 Hari Macromedia Flash 8. Yogyakarta: Andi.

[5] Murdiyatmoko, Janu. 2007. Sosiologi Memahami dan Mengkaji Masyarakat. Bandung: Grafindo Media Pratama.

[6] Permana, Budi. Ukar, Kurweni. 2010. 36 Jam Belajar Komputer Adobe Photoshop Cs5. Jakarta: Elex Media Komputindo.

[7] Suprapto, Tommy. 2009. Pengantar Teori dan Manajemen Komunikasi. Yogyakarta: Media Pressindo.

[8] Widjaja, Christanto. 2008. Kamera Video Editing. Jakarta: Widjaj. 